\title{
SEISMIC UPGRADATION OF TALL BUILDINGS
}

\author{
Mirza Aamir Baig ${ }^{*}{ }^{凶}(\mathrm{D})$, Tanveer Sultan Bhat ${ }^{2}$ \\ *1, 2 Department of Civil Engineering, Alfalah University, India
}

DOI: https://doi.org/10.29121/IJOEST.v4.i5.2020.107

Article Type: Research Article

Article Citation: Mirza Aamir Baig, and Tanveer Sultan Bhat. (2020). SEISMIC UPGRADATION OF TALL BUILDINGS. International Journal of Engineering Science Technologies, 4(5), 6-15.

https://doi.org/10.29121/IJOEST.v

4.i5.2020.107

Received Date: 25 August 2020

Accepted Date: 23 September 2020

Keywords:

Structural Motions

Damping

Passive and Active control devices TMD

AMD

\section{ABSTRACT}

High rises have involved interest for engineers for as long as century. All the more along these lines, the previous thirty years have seen various structures ascending starting from the earliest stage, resisting gravity. Burj Khalifa Dubai, Taipei, Petronas twin pinnacle, Empire state building are a portion of the living instances of designing wonders.

What befalls a structure when it arrives at such inconceivable statures separated from the awe that it will be, it additionally represents a gigantic measure of challenge for the auxiliary architect. Since then these structures are looked by administration stacking conditions. Two destroying powers of nature, wind and seismic tremor become truly basic for these structures. The harmony among firmness and pliability to be given turns into the controlling components to the plan of such structures. Routinely giving enough firmness against colossal burdens doesn't appear to fulfill the necessities. These structures are frequently given adequate pliability so as to disperse the gigantic measure of powers. In any case, there is a limit, with respect to how much malleability can be given in a structure. A fast figuring shows that the highest-level uprooting that can be securely borne by a 500 $\mathrm{m}$ tall structure is nearly $2 \mathrm{~m}$. The structure would not fall flat if its popular narrative dislodges by $2 \mathrm{~m}$.

Use of different sorts of dampers and isolators have been utilized in disseminating this vitality. Much exploration has gone into advancement of TMDs, ATMDs, BTMDs, and seismic base isolators. Examination has additionally gone into different kind of investigations method as more vigorous powerful examination, weakling investigation, time history investigation and execution-based investigation.

Here an endeavor has been made to explore the near benefits and negative marks of various sorts of auxiliary arrangements to comprehend their conduct under seismic and wind loads. The structure considered is of 50 stories. Different designs that have been considered incorporates propped frameworks, shear divider frameworks, dampers and isolators. The investigations results have been organized and plotted to comprehend their conduct. Time history examination and execution-based investigation by sucker investigation have additionally been concentrated to comprehend the conduct of structures. 


\section{INTRODUCTION}

A tall structure can't be characterized in a solitary definition. There are different qualities dependent on which it very well may be disclosed specifically Height Relative to Context, Proportion and Tall Building Technologies. Height as well as the setting decides the structure to be delegated tall structures.

Once more, a tall structure isn't just about stature yet in addition about extent. In low metropolitan foundations the structure which gives a slim look are delegated tall structures. While now and again the huge/enormous impression Buildings that are tall are not considered as tall structure because of their size/floor territory.

The structure dependent on advancements of being a result of "tall" (e.g., explicit Vertical vehicle innovations, basic breeze propping as a result of stature, and so on.), at that point this Building can be classed as a tall structure. Albeit number of floors is a helpless marker of characterizing a tall structure because of the changing floor to floor stature between varying structures and capacities (e.g., office versus private use), a structure of maybe at least 14 stories or more than 50 meters in tallness could maybe be utilized as an edge for thinking of it as a "tall structure.

However, what befalls a structure when it arrives at such incredible statures separated from the astonishment that it will be, it likewise represents a tremendous measure of challenge for the auxiliary architect. Since then these structures are looked by administration stacking conditions. Two destroying powers of nature, wind and seismic tremor become truly basic for these structures. The harmony among firmness and malleability to be given turns into the managing variables to the plan of such structures. Customarily giving enough solidness against tremendous burdens doesn't appear to fulfill the necessities. These structures are regularly given adequate malleability so as to disperse the colossal measure of powers. Yet, there is a limit, with regards to how much pliability can be given in a structure.

\subsection{STRUCTURAL SYSTEMS FOR TALL BUILDINGS}

Following are the Structural systems for tall buildings:

1) Rigid frame systems

2) Braced frame and shear-walled frame systems

3) Outrigger systems

4) framed-tube systems

5) braced-tube systems

6) bundled-tube systems

\subsection{OBJECTIVES}

Following are the main objectives of the work:

- Comparison of behavior of different structures of reinforced concrete (framed structures, braced systems, shear walls systems).

- Comparison of Effects of Seismic \& Wind Forces on High Rise Buildings with different structural configuration and to compare the key parameters.

- Study the impact of base isolation on the above structures.

-

Study the impact of dampers for the above structures

\section{METHOD OF ANALYSIS}

\subsection{STATIC ANALYSIS}

The static method is the simplest one-it requires less computational effort and is based on the formulae given in the code. First, the design base shear is computed for the whole building and it is then distributed along the height of the building. The lateral forces at each floor level thus obtained are distributed to individual lateral load resisting elements. 


\subsection{DYNAMIC ANALYSIS}

Dynamic analysis shall be performed to obtain the design seismic forces and its distribution to different levels along the height of building and to the various lateral load resisting elements in following cases:

- Regular Building - Greater than $40 \mathrm{~m}$ height in zone IV and V and those greater than $90 \mathrm{~m}$ in height in zone II and III.

- Irregular building - All framed buildings higher than $12 \mathrm{~m}$ in zone IV and V, and those greater than 40 $\mathrm{m}$ height in zone II and III.

- For irregular building lesser than $40 \mathrm{~m}$ in height in zone II and III, dynamic analysis even though not mandatory, is recommended.

\subsubsection{RESPONSE SPECTRUM METHOD}

Response spectrum method is simply a plot of peak or steady state response (displacement, velocity or acceleration of a series of oscillators of varying natural frequency that are forced into motion by same base vibration or shock.

\subsubsection{NON- LINEAR TIME HISTORY ANALYSIS}

It is an analysis of dynamic response of structure at each increment of time, when its base is subjected to any specific ground motion time history (compatible time history for medium soil IS-1893:2002-Part 1)

\subsection{PUSHOVER ANALYSIS (NON-LINEAR STATIC METHOD)}

Pushover method of analysis is a technique in which a structural is modeled with non-linear properties (such as steel yield, plastic hinges) and permanent gravity load is subjected to an incremental load applied laterally from ' 0 ' value to prescribed ultimate displacement or until the structure become unstable to withstand the further forces

\section{MODELS CONSIDERED FOR ANALYSIS}

Following six types of models have been considered for analysis. It was attempted to choose models that are representative of actual building types that are being constructed nowadays. Type $A$ is regular framed structure with columns. Type B hybrid braced framed structure wit

bracings of Type 1 in periphery and columns. Type $C$ hybrid braced framed structure with bracings of Type 2 in periphery and columns. Type $\mathrm{D}$ is tube in tube.

Table 1: Structural Description

\begin{tabular}{|c|c|}
\hline Model ID & Description \\
\hline Type A & Regular Frame Structure \\
\hline Type B & Hybrid braced framed structure with bracings in periphery \\
\hline Type C & hybrid braced framed structure with bracings in periphery and columns \\
\hline Type D & Tube structure with shear walls and columns \\
\hline Type E & Tube in Tube structure with shear walls and columns \\
\hline Type F & Simple framed structure with Tuned Mass Dampers \\
\hline Type G & Simple framed structure with Base Isolation \\
\hline
\end{tabular}



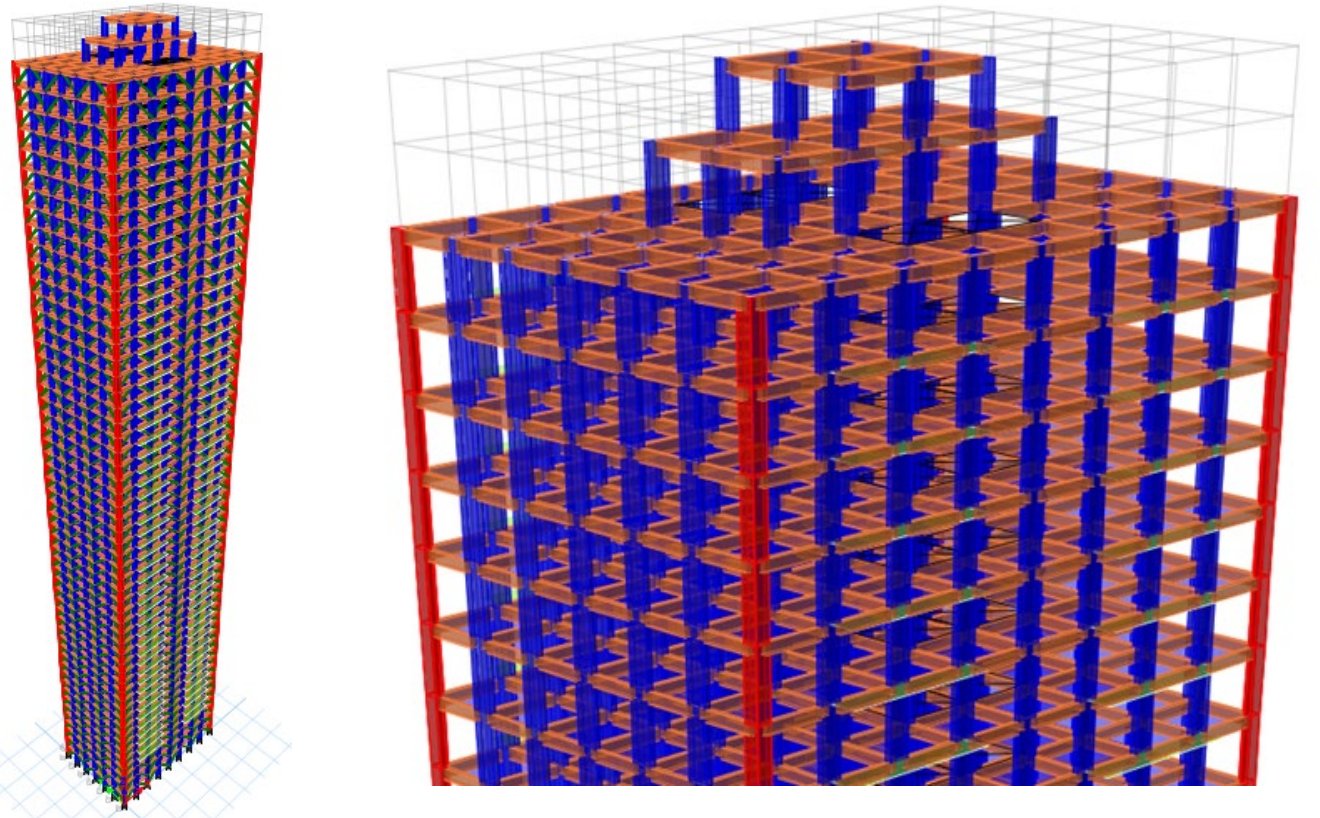

Figure 1: Base Model considered for Analysis
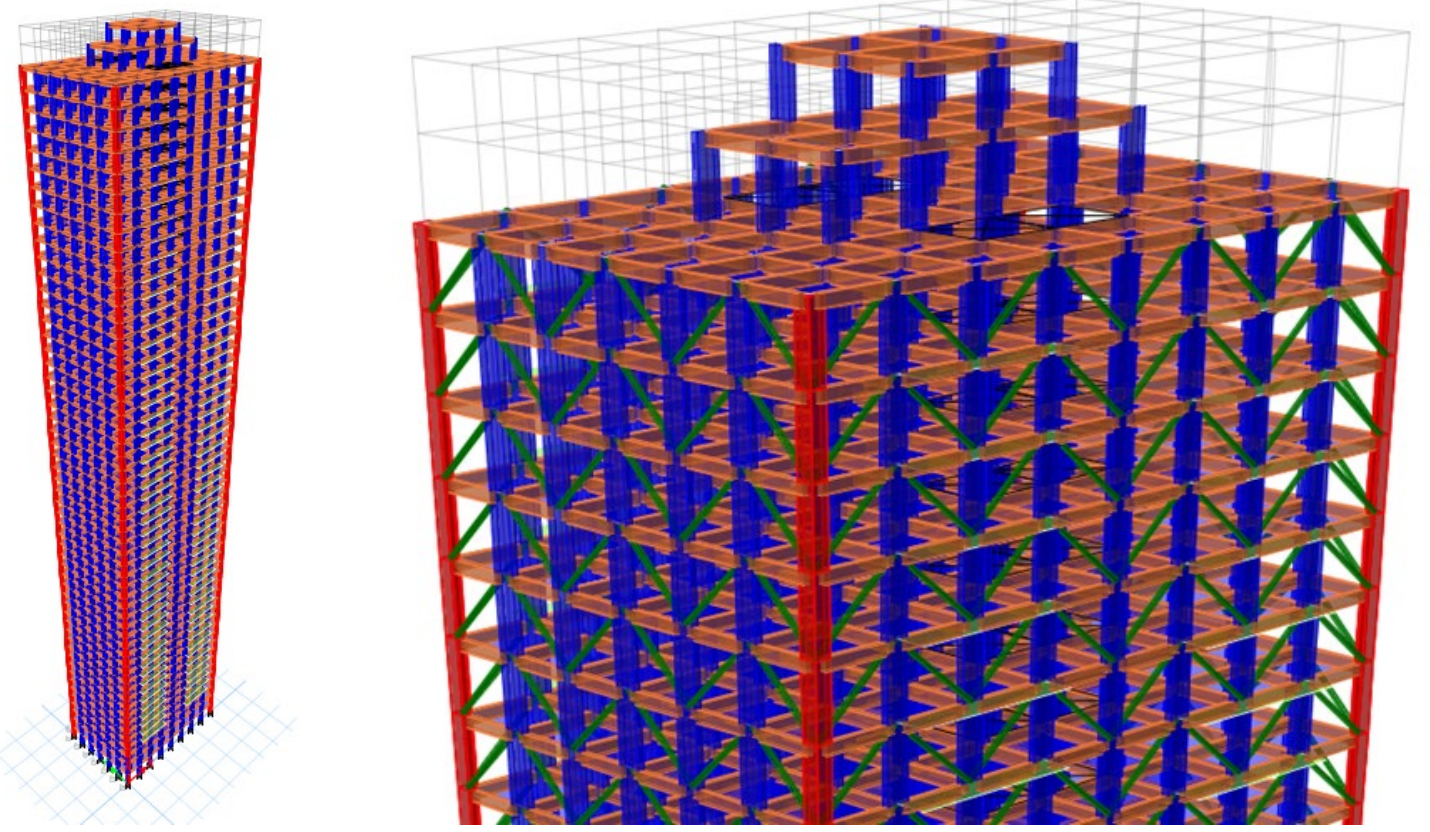

Figure 2: Hybrid braced framed structure with bracings in periphery

\section{MODEL PARAMETERS}

For the analysis of multi storied building six types of models have been considered for analysis. Type A is regular framed structure with columns. Type B hybrid framed structure with shear wall in periphery and columns. Type C hybrid framed structure with shear wall in centre and columns. Type D is tube structure. Type E is hybrid framed structure with lift core in centre. Type $\mathrm{F}$ is tube in tube system. All the different types of models considered are analysed for 50 storey.

In the current study main goal is to compare the Static and Dynamic Analysis of different types of building.

Design Parameters- Here the Analysis is being done for $\mathrm{G}+50$, (rigid joint regular frame) building by computer software using ETABS. 

frames

Design Characteristics - The following design characteristics are considered for Multi-storey rigid jointed

\section{Seismic Load}

As per IS: 1893, Noida is located in Seismic Zone IV.

Design base shear, V = Z I W Sa/2 R g

Wind Load

The wind velocity at Noida is $47 \mathrm{~m} / \mathrm{s}$. The other parameter of wind load as per IS: 875 (Part-3).

Table 2: Model Parameters

\begin{tabular}{|c|c|c|}
\hline S. No & Particulars & Dimension/Size/Value \\
\hline 1. & Model & $\mathrm{G}+50$ \\
\hline 2. & Seismic Zones & IV \\
\hline 3. & Floor height & $3 \mathrm{M}$ \\
\hline 4. & Basement & $4 \mathrm{M}$ \\
\hline 5. & Building height & $161.6 \mathrm{~m}$ \\
\hline 6. & Plan size & $0.3 \mathrm{~m} \times 0.75 \mathrm{~m}$ \\
\hline 8. & Size of columns & $0.3 \mathrm{~m} 0.75 \mathrm{~m} \& 0.3 \mathrm{mx} 0.6 \mathrm{~m}$ \\
\hline 9. & Size of beams & $125 \mathrm{~mm}$ \\
\hline 10 & Shear Walls & As per IS-1893-2002 \\
\hline 11. & Thickness of slab & \\
\hline 12. & Earthquake load & Type -II, Medium soil as per IS-1893 \\
\hline 13. & Type of soil &
\end{tabular}

\section{ANALYSIS RESULTS AND DISCUSSIONS}

The results of the models analysed have been tabulated and plotted here. More or less the results are as expected. The results are tabulated both individually for each type of building as well as for comparison between different models to study their comparative merit or demerit for each type of building.

Table 4: Base Shear $(\mathrm{kN})$

\begin{tabular}{|c|c|c|c|c|c|c|c|}
\hline \multicolumn{7}{|c|}{ Base Shear $(\mathrm{kN})$} & \\
\hline Load & Type A & Type B & Type C & Type D & Type E & Type F & Type G \\
\hline SPEC X & 4268.132 & 4481.458 & 4475.327 & 4727.562 & 5139.829 & 4388.14 & 11369.01 \\
\hline SPEC Y & 4268.117 & 4481.43 & 4475.322 & 4727.565 & 5063.677 & 4414.117 & 11137.94 \\
\hline WLX & 5145.435 & 5145.435 & 5145.435 & 5145.435 & 5145.435 & 5145.435 & 5145.435 \\
\hline WLY & 10080.85 & 10080.85 & 10080.85 & 10080.85 & 10080.85 & 10080.85 & 10080.85 \\
\hline
\end{tabular}

Table 3: Seismic Parameter

\begin{tabular}{|c|c|c|c|c|}
\hline \multicolumn{5}{|c|}{ Seismic Parameters } \\
\hline \multicolumn{2}{|c|}{ Seismic Zone $(\mathrm{Z})$} & IV & Soil Type (S) & Medium \\
\hline \multicolumn{2}{|c|}{ Response Reduction Factor (R) } & 5 & Importance Factor (I) & 1 \\
\hline \multicolumn{2}{|c|}{ Seismic Weight $(\mathrm{W})$} & 480435.44 & Zone Factor & 0.24 \\
\hline \multicolumn{2}{|c|}{ Total Height (m) } & 170 & Length along $\mathrm{X}(\mathrm{m})$ & 32 \\
\hline \multicolumn{2}{|c|}{ Basement Height (m) } & 8 & Width along Y (m) & 21 \\
\hline \multicolumn{2}{|c|}{ Height of Mumty (m) } & 0 & Effective Height (m) & 170 \\
\hline \multicolumn{2}{|c|}{ Acceleration, $\mathrm{g}\left(\mathrm{mm} / \mathrm{s}^{2}\right)$} & 9806.65 & Default Scale Factor & 980.67 \\
\hline EQX & -4431.816 & $0.00 \mathrm{E}+00$ & \multirow[t]{2}{*}{ Scale X } & 1.00 \\
\hline EQY & $0.00 \mathrm{E}+00$ & -4431.8159 & & 980.67 \\
\hline SPECX & 4431.8012 & 0.0012 & \multirow[t]{2}{*}{ Scale Y } & 1.00 \\
\hline SPECY & 0.0006 & 4431.8136 & & 980.67 \\
\hline
\end{tabular}


Seismic Upgradation of Tall Buildings

\begin{tabular}{|c|c|c|c|c|c|c|c|}
\hline \multirow{2}{*}{\multicolumn{2}{|c|}{$\begin{array}{c}\text { Detail } \\
\text { Bare Frame }\end{array}$}} & \multicolumn{2}{|c|}{ Time Period (s) } & $\mathrm{S}_{\mathrm{a}} / \mathrm{g}$ & \multirow{2}{*}{$\frac{A_{h}}{0.0092}$} & \multirow{2}{*}{$\frac{V_{B}}{4441}$} & \multirow{2}{*}{$\begin{array}{c}\% A_{h} \\
0.92 \%\end{array}$} \\
\hline & & $\mathrm{T}_{\mathrm{a}}$ & 3.531 & 0.385 & & & \\
\hline Above Basement & & $\mathrm{T}_{\mathrm{a}}$ & 3.406 & 0.399 & 0.0096 & 4605 & $0.96 \%$ \\
\hline \multirow{2}{*}{\multicolumn{2}{|c|}{ With Infil }} & $\mathrm{T}_{\mathrm{x}}$ & 2.705 & 0.503 & 0.0121 & 5798 & $1.21 \%$ \\
\hline & & $\mathrm{T}_{\mathrm{y}}$ & 3.339 & 0.407 & 0.0098 & 4697 & $0.98 \%$ \\
\hline \multirow{2}{*}{\multicolumn{2}{|c|}{ Avarage }} & $\mathrm{T}_{\text {avgx. }}$ & 3.118 & 0.436 & 0.0105 & 5030 & $1.05 \%$ \\
\hline & & $\mathrm{T}_{\text {avgy. }}$ & 3.435 & 0.396 & 0.0095 & 4565 & $0.95 \%$ \\
\hline \multirow{2}{*}{\multicolumn{2}{|c|}{ Above Basement }} & $\mathrm{T}_{\mathrm{x}}$ & 2.577 & 0.528 & 0.0127 & 6084 & $1.27 \%$ \\
\hline & & $\mathrm{T}_{\mathrm{y}}$ & 3.182 & 0.427 & 0.0103 & 4929 & $1.03 \%$ \\
\hline \multirow[t]{2}{*}{ Without Mumty } & & $\mathrm{T}_{\mathrm{x}}$ & 2.705 & 0.503 & 0.0121 & 5798 & $1.21 \%$ \\
\hline & & $\mathrm{T}_{\mathrm{y}}$ & 3.339 & 0.407 & 0.0098 & 4697 & $0.98 \%$ \\
\hline \multicolumn{8}{|c|}{ Building Lateral Displacement Check } \\
\hline \multirow[t]{4}{*}{ Permissible } & WLX & 340 & \multirow[t]{4}{*}{ Actual } & WLX & \multicolumn{2}{|c|}{267.5} & SAFE \\
\hline & WLY & 340 & & WLY & \multicolumn{2}{|c|}{627} & FAIL \\
\hline & EQX & 680 & & SPECX & \multicolumn{2}{|c|}{272} & SAFE \\
\hline & EQY & 680 & & SPECY & \multicolumn{2}{|c|}{331.9} & SAFE \\
\hline \multirow[t]{4}{*}{ Permissible } & WLX & 340 & \multirow[t]{4}{*}{ Actual } & DL+WLX & \multicolumn{2}{|c|}{267.5} & SAFE \\
\hline & WLY & 340 & & DL+WLY & \multicolumn{2}{|c|}{627} & FAIL \\
\hline & EQX & 680 & & DL+SPECX & \multicolumn{2}{|c|}{272} & SAFE \\
\hline & EQY & 680 & & DL+SPECY & \multicolumn{2}{|c|}{331.9} & SAFE \\
\hline \multirow[t]{4}{*}{ Permissible } & WLX & 340 & \multirow[t]{4}{*}{ Actual } & DL-WLX & \multicolumn{2}{|c|}{267.5} & SAFE \\
\hline & WLY & 340 & & DL-WLY & \multicolumn{2}{|c|}{627} & FAIL \\
\hline & EQX & 680 & & DL-SPECX & \multicolumn{2}{|c|}{272} & SAFE \\
\hline & EQY & 680 & & DL-SPECY & \multicolumn{2}{|c|}{331.9} & SAFE \\
\hline
\end{tabular}

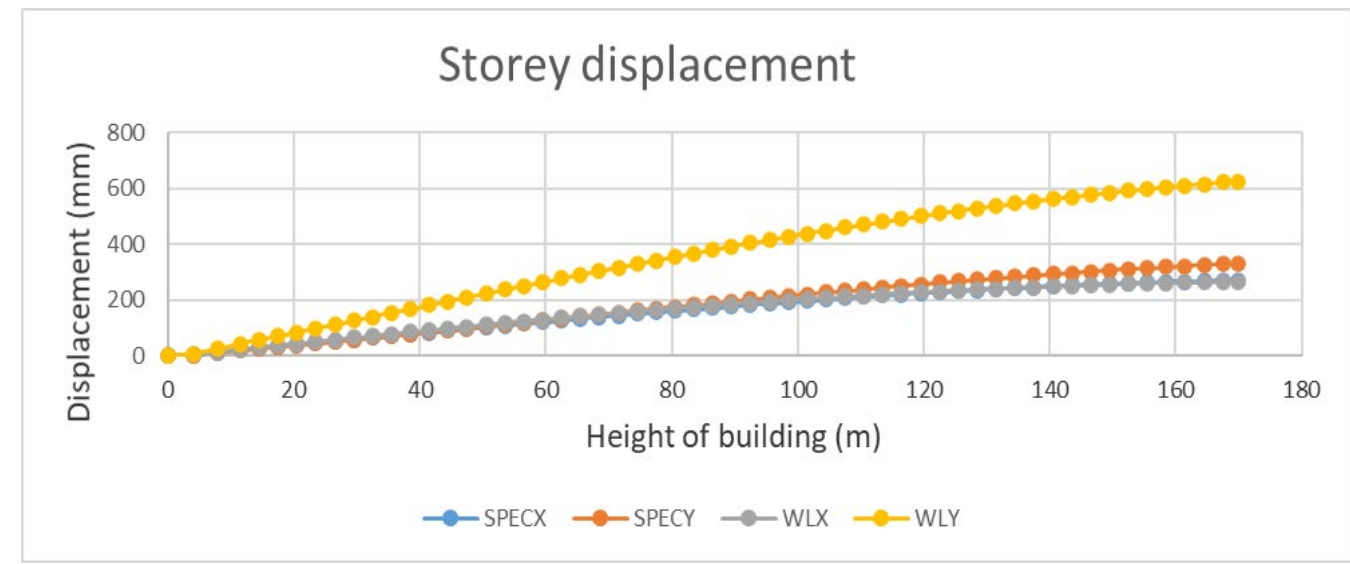

Figure 3: Storey displacement Type A

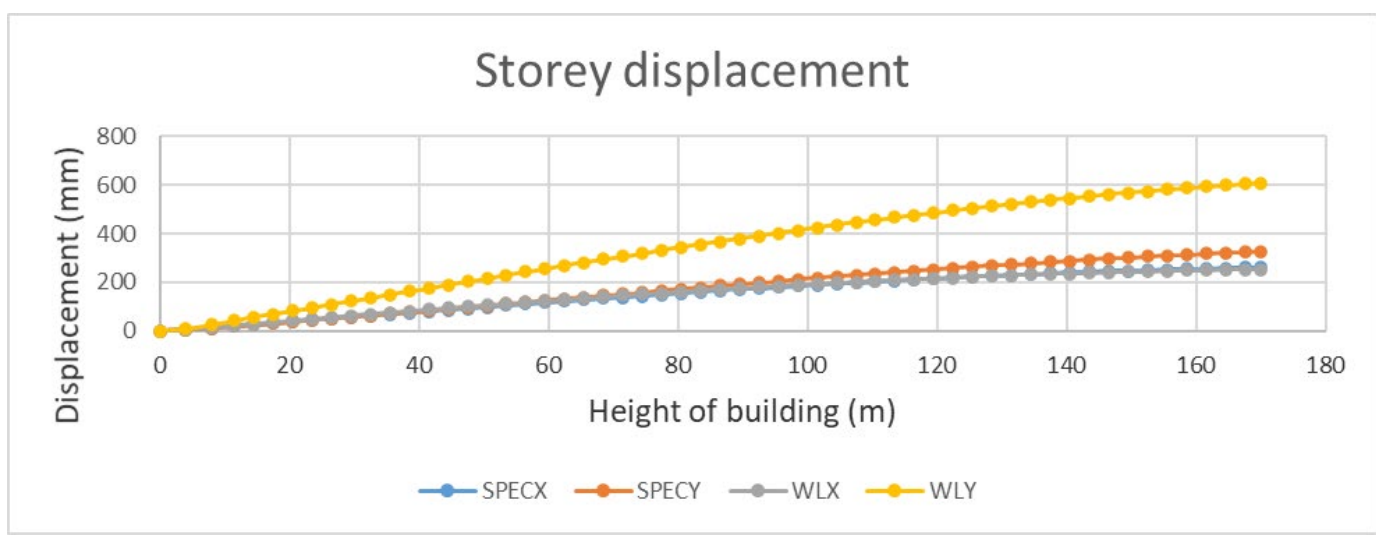

Figure 4: Storey displacement Type B 


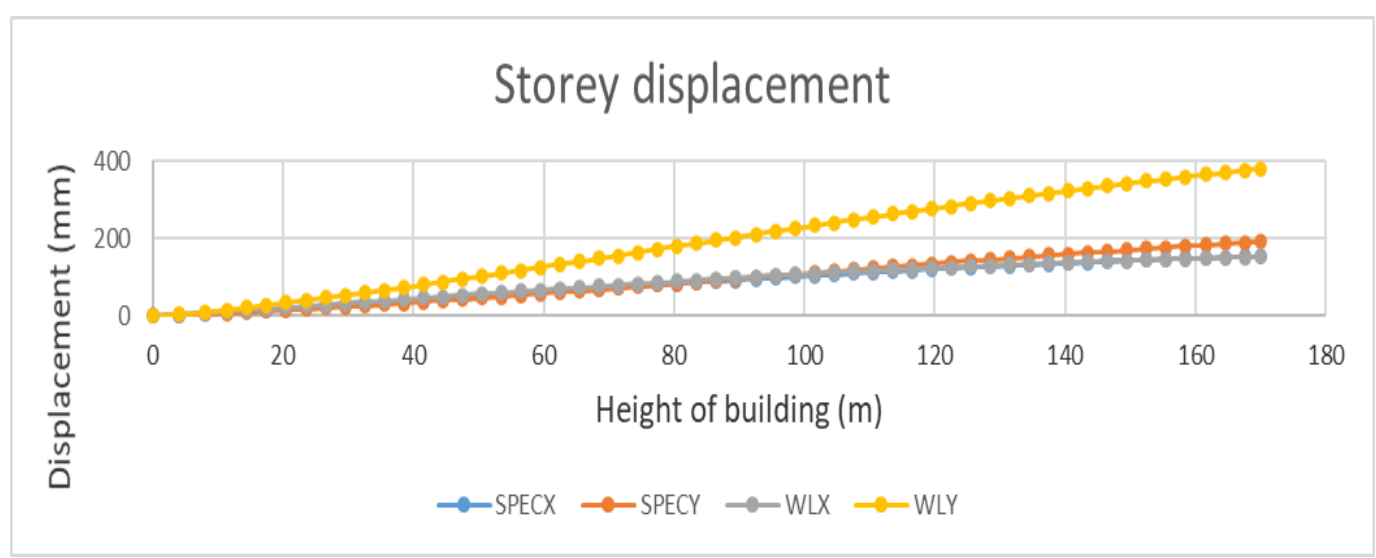

Figure 5: Storey displacement Type C

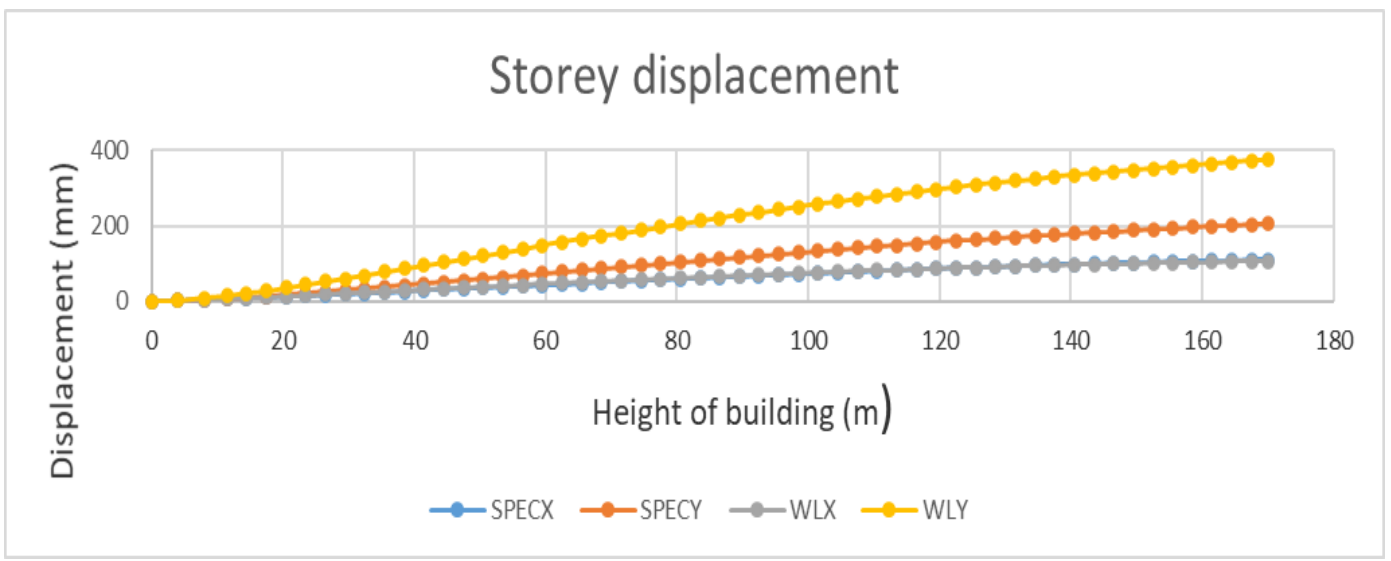

Figure 6: Storey displacement Type D

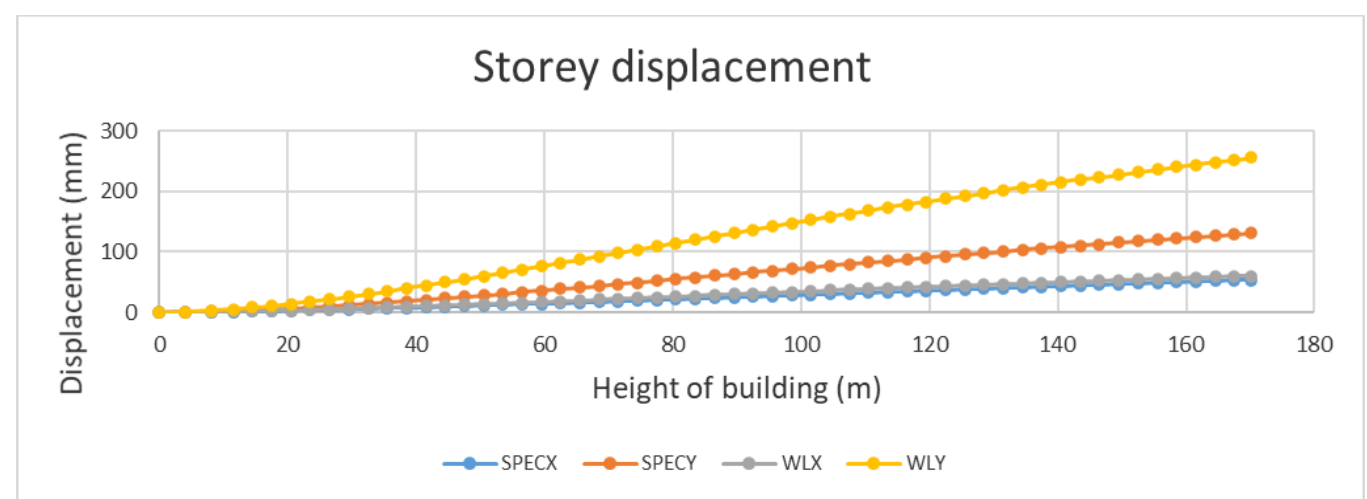

Figure 7: Storey displacement Type E

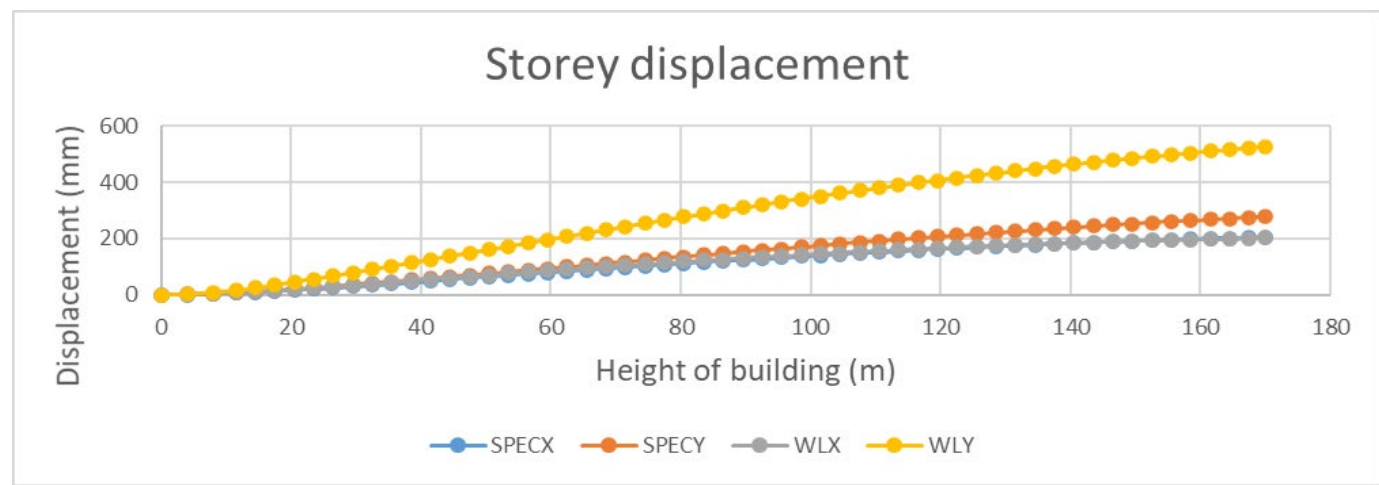

Figure 8: Storey displacement Type F 


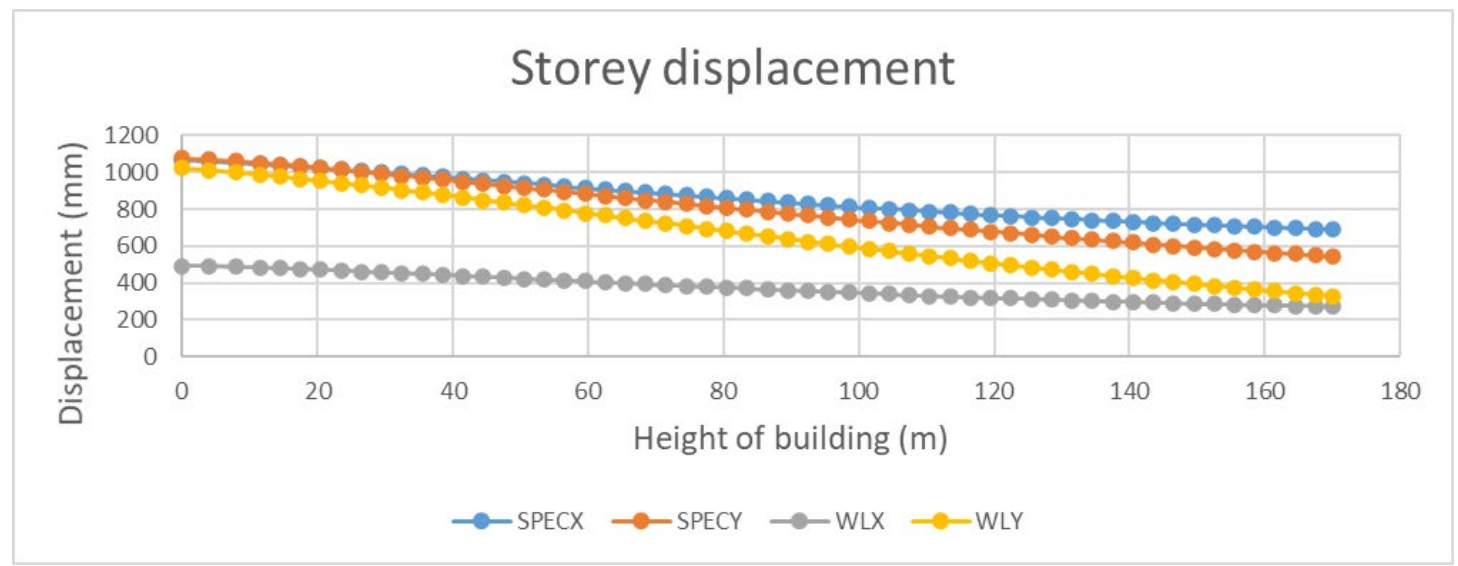

Figure 9: Storey displacement Type G

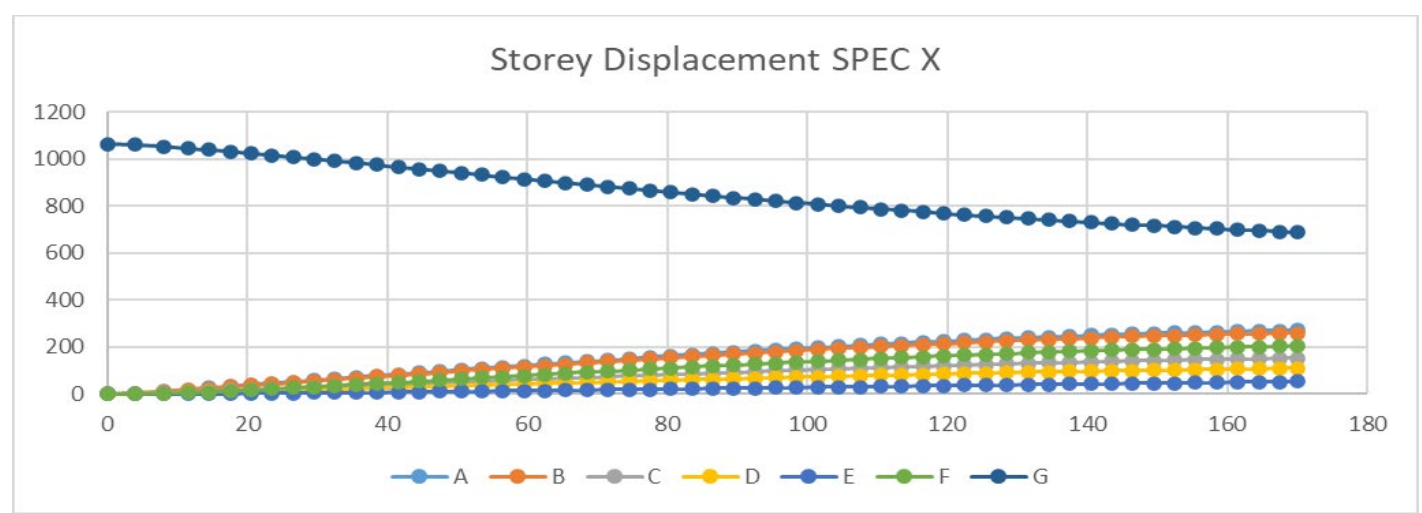

Figure 10: Storey displacement Type A

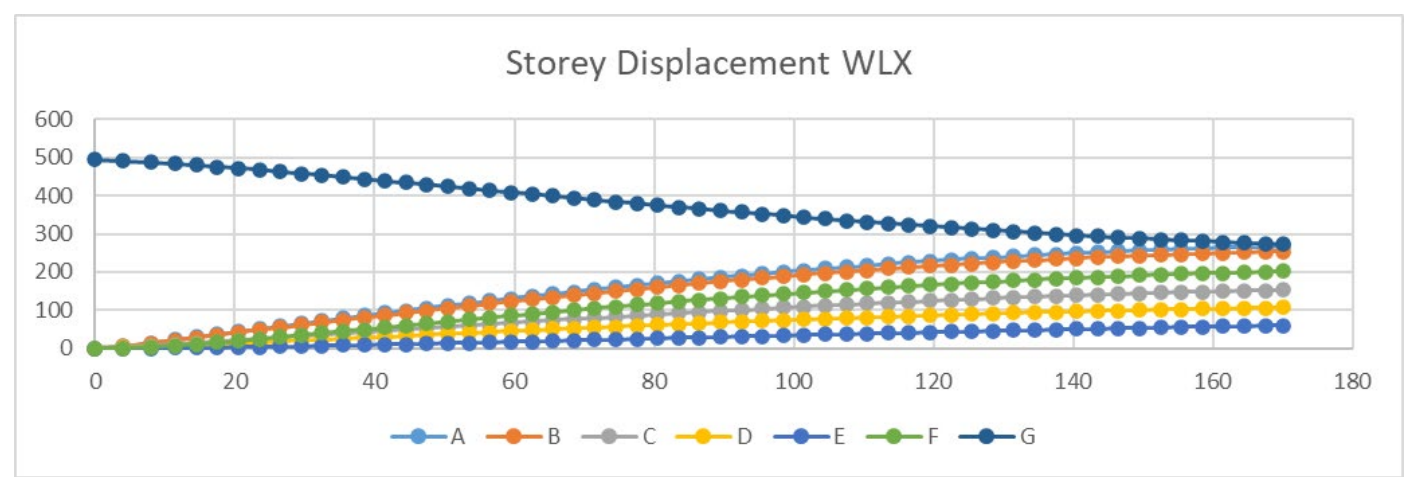

Figure 11: Storey displacement Type A

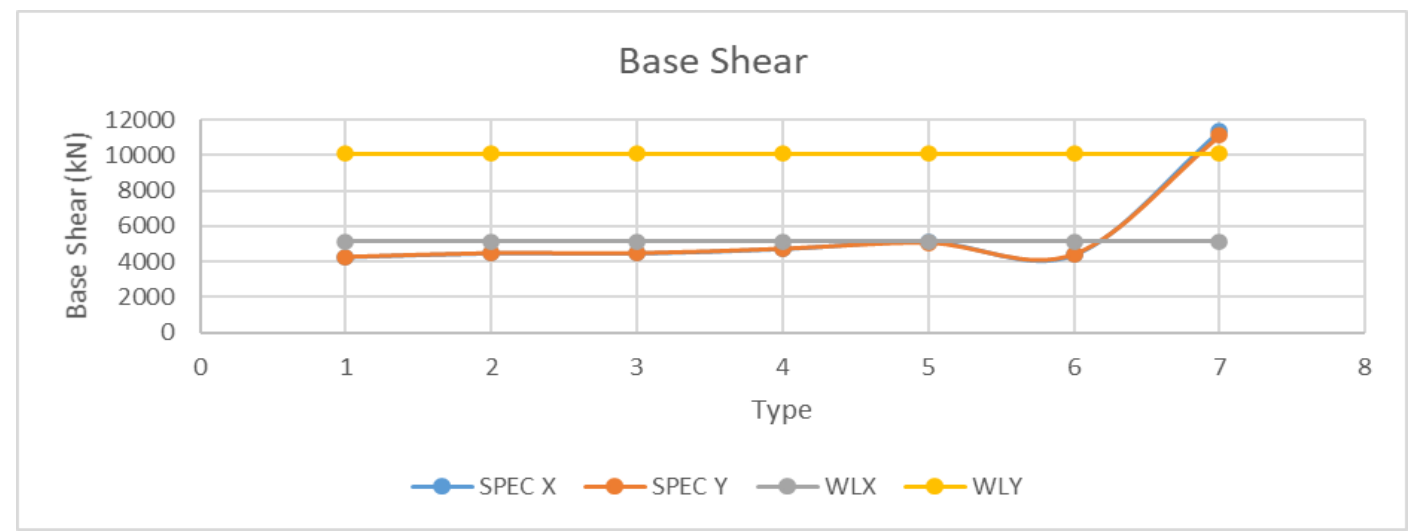

Figure 12: Base Shear $(\mathrm{kN})$ 


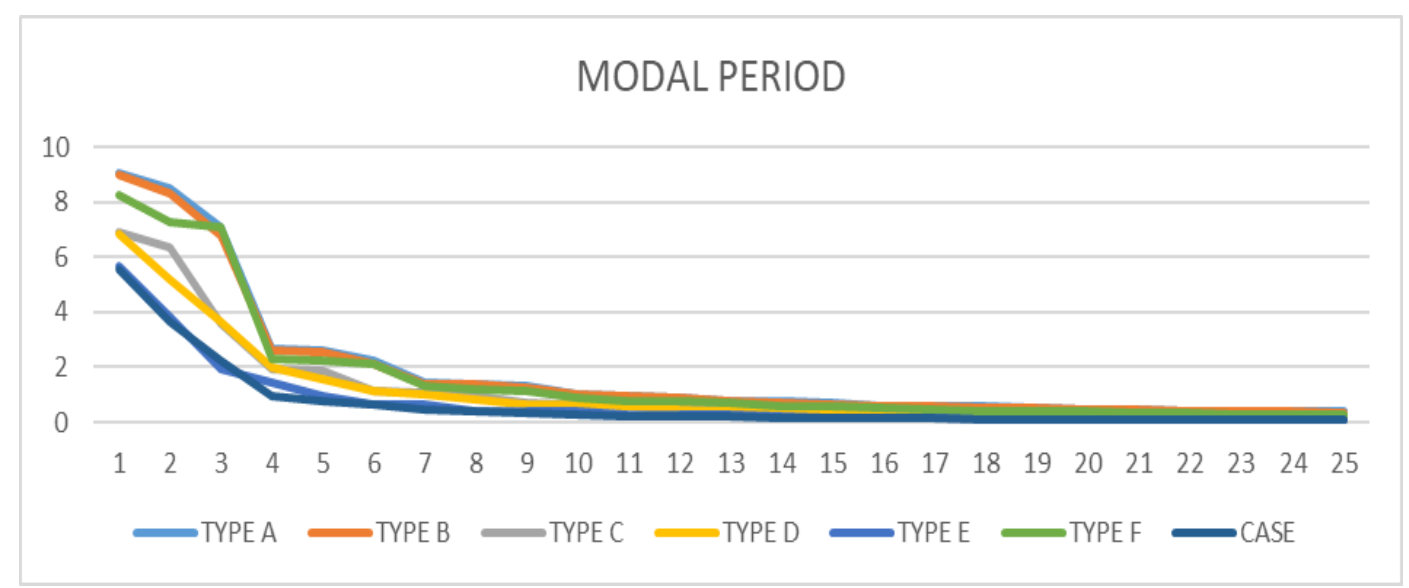

Figure 13: Modal Period

\section{CONCLUSIONS}

Seven kinds of models have been considered for investigation alongside one contextual analysis. It was endeavored to pick models that are illustrative of genuine structure types that are being built these days. Care was taken to join the central ideas overseeing the plan of mixture creative tall structures being developed nowadays. Type An is customary encircled structure with sections. Type B mixture surrounded structure with supporting in the fringe at each straight on each floor. Type $C$ crossover confined structure with propping in the outskirts at various coves and various stories. Strikingly this sort works superior to normal supporting. Type D is tube structure. Type E is Tube in Tube framework. Type F was demonstrated with Tuned Mass Dampers. Type G was displayed with Base Isolators. Furthermore, one complete structure with 5BHK level having bars, sections and shear dividers demonstrated in the structure was likewise investigated for examinations.

A gander at the correlation plots for reactions of the apparent multitude of types recommend the accompanying ends. Type G, model with base separation has the most extreme base shear just as story removal at the base. This is the admissible uprooting so as to disperse the vitality which is advantageous for the structure.

In diminishing request of base shear, we have the models separately as Type $E$ (Tube in Tube), Type D (Tube), Type B (Bracing Type 1), Type C (Bracing Type 2), Type F (Model with Tuned Mass Dampers) lastly Type A (Regular Framed). It is intriguing to take note of that Type A despite everything pulls in the least base shear and is the most lightweight structure.

Both the supported structures indicated one exceptionally fascinating conduct. Type $\mathrm{C}$, where supporting has been done at a hole of not many floors is a lot lighter than Type B, where propping has been done at each floor. Yet, the story removal of Type $C$ is greatly diminished than Type B. We may reason that, in the event that supporting framework is picked, at that point propping as given by Type $\mathrm{C}$ is generally appropriate for tall structures. Type $\mathrm{B}$ while compelling somewhat isn't a lot of prudent.

Tube in Tube frameworks, as in the event of Type E pulls in much base shear than Tube structures as in Type D, however the dislodging is significantly less. This is ideal where our structure is adequately hefty just as unbending. Shear dividers are viable in structures just up to certain stature limits, as a rule inside 35 - 40 stories, yet structures as Tube or Tube in Tube perform far superior to standard shear divider structures.

Type F is our model with Tuned Mass Dampers. It is seen that the mass of the structure isn't expanded by more than 1 - 2 percent of the mass of the standard structure, yet its relocations are extensively decreased. This is in effect obviously approved by the reaction of Type F model which has practically same base shear as Type A, however considerably less story removal than Type A.

The methodology for plan of structures for wind and quake are askew separated. Wind powers are by and large push powers that attempts to overturn or curve the structure vertically. They are material on the uncovered substance of the structures. So as to defend the structure for wind, one extremely straightforward arrangement can be to make the structure heavier. Heavier the structure, better its capacity to oppose wind powers.

In any case, tremor powers are very surprising. They are essentially latency powers, which rely upon the mass of the structures. The structures on activity of tremor powers infrequently overturn or tumble down. They really breakdown simply under its own vertical pivot. Since quake powers rely on the weight/mass of the structure, heavier 
the structure, more seismic tremor drive it pulls in. The thought is to make the structure lighter. Lighter the structure, better it is for the structure to oppose seismic tremor powers.

To have the option to adjust, these two opposing standards of configuration is a genuine test for auxiliary architects.

\section{SOURCES OF FUNDING}

This research received no specific grant from any funding agency in the public, commercial, or not-for-profit sectors.

\section{CONFLICT OF INTEREST}

The author have declared that no competing interests exist.

\section{ACKNOWLEDGMENT}

None.

\section{REFERENCES}

[1] Ashik S. Parasiya Paresh Nimodiya "A review on comparative analysis of brace frame with conventional lateral load resisting frame in rcc structure using software".

[2] Suresh P, Panduranga Rao B, Kalyana Rama J.S "Influence of diagonal braces in RCC Multi-storied frames under wind loads: A case study

[3] Umesh. R. Biradar, Shivaraj Mangalgi "seismic response of reinforced concrete structure by using different bracing systems".

[4] Mohammed yousuf, P.M. shimpale "Dynamic Analysis of Reinforced Concrete Building with Plan Irregularities".

[5] Mr. S. Mahesh, Mr. Dr. B. Panduranga Rao "Comparison of analysis and design of Regular and irregular configuration of multi-Story building in various seismic zones and Various types of soils using ETABS and STAAD".

[6] Nauman Mohammed, Islam Nazrul "Behaviour of Multistorey RCC Structure with Different Type of Bracing System (A Software Approach)".

[7] S. Zubair Ahmed, K.V. Ramana, Ramancharla Pradeep Kumar "Seismic Response of RC frame structure with soft storey".

[8] Jain. S K, IIT Roorkee Review of Indian seismic code, IS 1893 (Part 1): 2002

[9] Reddy K. R. C, Sandip A. Tupat (2012). "The effect of zone factors on wind and earthquake loads of high-rise structures".

[10] Shahzad Jamil Sardar and Umesh. N. Karadi (2014) "effect of change in shear wall Location on storey drift of multistory building subjected to lateral loads".

[11] S.R. Thorat and P.J. Salunke "Seismic Behaviour of Multistorey Shear Wall Frame Versus Braced Concrete Frames".

[12] David T. Finley, Ricky A. Cribbs "Equivalent Static vs. Response Spectrum A Comparison of Two Methods".

[13] Kareem, A., Kijewski, Y, "Mitigation of Motions of Tall Buildings with Specific Examples of Recent Applications," Wind and Structures., Vol. 2, No. 3, pp. 201-251 (2018).

[14] Soong, T.T. and G.F. Dargush. (2017), Passive Energy Dissipation Systems in Structural Engineering, Wiley \& Sons, New York.

[15] Housner, G.W., et al. (1997), Structural Control: Past, Present and Future, Special Issue of Journal of Engineering Mechanics, 123(9).

[16] Kwok, K.C.S. and N. Isyumov. (July 20188), Aerodynamic Measures to Reduce the Wind-Induced Response of Buildings and Structures, Proceedings of Structural Engineers World Congress, San Francisco, CD-ROM: T179-6. 